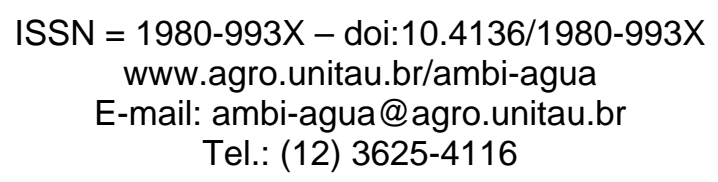

\title{
Capacidade extratora de diferentes espécies vegetais cultivadas em sistemas alagados utilizados no tratamento de águas residuárias da suinocultura
}

(doi:10.4136/ambi-agua.84)

\author{
Antonio Teixeira de Matos ${ }^{1}$; Wallisson da Silva Freitas²; Paola Alfonsa Vieira Lo \\ Monaco $^{3}$ \\ ${ }^{1}$ Universidade Federal de Viçosa - UFV \\ E-mail: atmatos@ufv.br \\ ${ }^{2}$ Instituto Federal de Educação, Ciência e Tecnologia do Norte de Minas Gerais \\ E-mail: wallfreitas@yahoo.com.br \\ ${ }^{3}$ Instituto Federal de Educação, Ciência e Tecnologia do Espírito Santo \\ E-mail: paolalomonaco2004@yahoo.com.br
}

\section{RESUMO}

Objetivou-se, neste trabalho, avaliar a capacidade extratora de diferentes espécies vegetais quando cultivadas em sistemas alagados construídos (SACs) utilizados no tratamento de águas residuárias de suinocultura (ARS). Para isso, foram construídos 4 SACs de 24,0 m x $1,1 \mathrm{~m} \times 0,7 \mathrm{~m}$, impermeabilizados com geomembrana de policloreto de vinila (PVC) e preenchidos com 0,4 m de brita zero. Nos SAC1, SAC2 e SAC3, cultivou-se taboa (Typha latifolia L.), Alternanthera philoxeroides (Mart.) Griseb. e capim tifton-85 (Cynodon dactylon Pers.), respectivamente. No SAC4 foi plantada a Alternanthera no $1^{\circ}$ terço, Typha no $2^{\circ}$ terço e tifton-85 no $3^{\circ}$ terço do leito. Após passar por um filtro orgânico preenchido com bagaço de cana-de-açúcar picado, a ARS foi aplicada nos SACs numa vazão de $0,8 \mathrm{~m}^{3} \mathrm{~d}^{-1}$, o que proporcionou um tempo de residência hidráulica de 4,8 dias. Verificou-se tendência de se obter maiores extrações de poluentes pelas plantas cultivadas no início dos SACs. A Alternanthera foi a espécie vegetal que apresentou maior capacidade extratora de nutrientes, extraindo 9,5 e 23\% de todo o N-total e K aplicados via ARS. As plantas extraíram pequenas quantidades de cobre da ARS. Em razão do melhor desempenho das plantas, recomenda-se o cultivo de Alternanthera ou ou de capim Tifton 85 em SACs a serem utilizados no tratamento de ARS.

Palavras-chave: dejetos de suínos; sistemas wetlands; tratamento de resíduos.

\section{Extractor capacity of different plant species cultivated in wetlands used to pig wastewater treatment}

\begin{abstract}
The objective of this study was to evaluate the extracting capacity of different plant species when cultivated in constructed wetlands systems (CWS) for the treatment of pig wastewaters (PW). For this, four CWS were constructed with $24.0 \mathrm{~m} \mathrm{x} 1.1 \mathrm{~m} \mathrm{x} 0.7 \mathrm{~m}$, sealed with geomembrane of polyvinyl chloride (PVC) and filled with $0.4 \mathrm{~m}$ of gravel "zero". In CWS1, CWS2 and CWS3 were planted cattail (Typha latifolia L.), Alternanthera philoxeroides (Mart.) Griseb. and grass-Tifton 85 (Cynodon dactylon Pers.), respectively. In CWS4 was planted Alternanthera in the 1st third, Typha in the 2nd third and tifton-85 in the 3rd third of the bed. After passing through a organic filter filled with crushed sugar cane bagasse, the ARS was applied in SACS in a flow of $0.8 \mathrm{~m}^{3} \mathrm{~d}^{-1}$, which provided a detention time of 4.8 days. There was a $\mathrm{t}$ rend to obtain higher extraction of pollutants by plants grown at the
\end{abstract}


MATOS, A. T.; FREITAS, W. S.; LO MONACO, P. A. V. Capacidade extratora de diferentes espécies vegetais cultivadas em sistemas alagados utilizados no tratamento de águas residuárias da suinocultura. Ambi-Agua, Taubaté, v. 4, n. 2, p. 31-45, 2009. (doi:10.4136/ambi-agua.84)

beginning of the CWS. The Alternanthera plant species that was presented greater capacity for nutrient extractor, extracting 9.5 and $23 \%$ of all total-N and K applied through ARS. Plants extracted small amounts of copper from the ARS. Because of the improved performance of plants, Alternanthera or Tifton-85 grass must be cultivated in CWS for the ARS treatment.

Keywords: pig wastes; wetlands systems; waste treatment.

\section{INTRODUÇÃO}

A suinocultura é uma atividade pecuária que, em escala comercial, se expandiu muito nas últimas décadas, devido ao aumento na demanda de carnes e de derivados de suíno, sendo uma atividade importante do ponto de vista social, econômico e, especialmente, de fixação do homem no campo.

O desenvolvimento da suinocultura tem como fator de maior preocupação a quantidade de dejetos produzidos, que apresentam alto poder poluente, especialmente quando lançados sem tratamento em corpos hídricos. Para Konzen (2003), a produção diária de águas residuárias varia de 12 a 15 litros por suíno. Em geral, águas residuárias da suinocultura contêm matéria orgânica, nitrogênio, fósforo, potássio, cálcio, sódio, magnésio, manganês, ferro, zinco, cobre e outros elementos incluídos nas dietas dos animais (Diesel et al., 2002). Dentre as soluções simples, propostas para tratamento de águas residuárias ricas em material orgânico, como é o caso das provenientes de granjas suinícolas, distingue-se a sua disposição em sistemas alagados construídos por ser uma forma viável e barata para seu tratamento.

Os sistemas alagados construídos têm sido propostos e utilizados no tratamento de várias águas residuárias, tais como as domésticas (Brasil et al., 2007), de laticínios (Matos et al., 2008), da lavagem/despolpa de frutos do cafeeiro (Fia et al., 2008) e outras.

Dentre os componentes fundamentais de sistemas alagados construídos estão as macrófitas aquáticas neles cultivadas, o substrato e o biofilme de bactérias formado no meio, responsáveis, direta ou indiretamente, pela ocorrência dos mecanismos de remoção de poluentes associados a esses sistemas (Marques, 1999). A escolha da espécie vegetal é, juntamente com outras variáveis de dimensionamento, de fundamental importância para o sucesso do tratamento de águas residuárias em sistemas alagados construídos. Dentre as funções das macrófitas aquáticas, estão incluídas: remoção de nutrientes da água residuária; transferência de oxigênio para o substrato; servir de suporte (rizomas e raízes) para o crescimento de biofilme de bactérias, além de melhoria na permeabilidade do substrato e na estética do ambiente (Campos, 1999; Lautenschlager, 2001; Marques, 1999; USEPA, 1988; Wetland International, 2003).

As plantas utilizam nutrientes dos SACs para o seu crescimento, atuando, desse modo, como extratoras de grande parte dos macro e micronutrientes da água residuária em tratamento. No entanto, quando morrem, elas devolvem os nutrientes para o sistema na forma orgânica, sendo necessário, portanto, serem efetuadas colheitas periódicas, evitando-se o acúmulo da massa vegetal e a consequente salinização do meio (Matos e Lo Monaco, 2003; Brix, 1997) diminuindo a capacidade das plantas se desenvolverem e a eficiência do sistema na remoção de poluentes. Segundo Lautenschlager (2001), a remoção de nutrientes pelas plantas é um dos principais fatores responsáveis pela reciclagem de sais minerais. Essas plantas removem, ainda, substâncias contendo metais pesados e compostos orgânicos tóxicos.

No período de crescimento, as plantas podem absorver macronutrientes (N e P) e micronutrientes (incluindo metais), entretanto, no início da senescência, a maior parte dos nutrientes é translocada para as raízes e rizomas. A estimativa anual de absorção de nitrogênio e fósforo por macrófitas emergentes varia de 12 a 120 g m-2 ano-1 e 1,8 a 18 g m2 ano-1, respectivamente (Reddy e DeBusk, 1985). A remoção de nitrogênio com as colheitas 
MATOS, A. T.; FREITAS, W. S.; LO MONACO, P. A. V. Capacidade extratora de diferentes espécies vegetais cultivadas em sistemas alagados utilizados no tratamento de águas residuárias da suinocultura. Ambi-Agua, Taubaté, v. 4, n. 2, p. 31-45, 2009. (doi:10.4136/ambi-agua.84)

da biomassa aérea varia de 7,4 a 18,9 g m-2 ano-1 (Mander et al., 2004) e a de fósforo varia de 0,4 a 10,5 g m-2 ano-1 em Phalaris arundinacea; de 0,6 a 9,8 g m-2 ano-1 em Phragmites australis; e de 0,2 a 6,5 g m-2 ano-1 em Typha spp. (Vymazal, 2004). Para SAC utilizado no tratamento de esgoto urbano, a absorção pelas macrófitas é estimada em 1,9\% do nitrogênio aportado ao sistema (Langergraber, 2004). A remoção de $\mathrm{N}$ pelas plantas, em SACs cultivados com Scirpus californicus, foi $50 \%$ do $\mathrm{N}$ aplicado, tendo ocorrido numa taxa de 1,41 g m-2 d-1 de N (Adcock et al., 1994; Rogers et al., 1991; Busnardo et al., 1992; citados por Lautenschlager, 2001).

A extração de metais pesados pelas raízes é de papel secundário em SACs, uma vez que somente pequena quantidade de metal pode ser removida por este mecanismo. No entanto, as plantas criam ambiente na zona radicular que pode proporcionar a imobilização de metais por processos oxidativos e redutivos (Whiting e Terry, 1999; Dunbabin e Bowmer, 1992; citados por Ye et al., 2001). Ye et al. (2001) construíram quatro SACs, cultivados com taboa (Typha latifolia L.), para tratar subproduto da combustão de carvão nos EUA. As plantas absorveram quantidades relativamente pequenas dos metais presentes nas águas residuárias, tendo sido obtidas remoções de apenas 0,91; 4,18; 0,19 e 0,38\%, respectivamente do Fe, $\mathrm{Mn}$, Cu e Ni aportados ao sistema.

Por existir pouca informação sobre o desempenho de espécies vegetais na extração de nutrientes em águas residuárias em sistemas alagados construídos, neste trabalho, teve-se como objetivo avaliar a capacidade extratora de diferentes espécies vegetais quando cultivadas em sistemas alagados construídos utilizados no tratamento de águas residuárias de suinocultura.

\section{MATERIAL E MÉTODOS}

O experimento foi conduzido na Área Experimental de Hidráulica, Irrigação e Drenagem do Departamento de Engenharia Agrícola da Universidade Federal de Viçosa - DEA/UFV, em Viçosa, Minas Gerais.

A água residuária da suinocultura (ARS) usada no experimento foi captada, por bombeamento, de um leito de alvenaria de dimensões de 4 × 5 × 2 metros, utilizado para coletar as águas residuárias provenientes da suinocultura da UFV, localizado próximo à referida Área Experimental. Antes de bombear a ARS para a Estação Experimental de Tratamento, fazia-se, por meio de sistemas de registros e tubos, a recirculação da ARS, a fim de homogeneizá-la no leito.

As parcelas experimentais foram constituídas por quatro SACs com fluxo horizontal subsuperficial, construídos em paralelo, em valas escavadas no solo, com dimensões de 0,7 m de altura (sendo 0,40 $\mathrm{m}$ de altura de substrato), 1,1 $\mathrm{m}$ de largura e 24,0 $\mathrm{m}$ de comprimento, impermeabilizados com geomembrana de polietileno de alta densidade (PEAD), com espessura de $0,5 \mathrm{~mm}$. Todos os SACs tinham declividade do fundo de $0,005 \mathrm{~m} \mathrm{~m}^{-1}$. O nível da água residuária foi mantido rente ao nível superior do substrato, no final dos SACs. Como meio de suporte, utilizou-se brita 0 , a qual apresentou volume de vazios de $48,4 \%$ e condutividade hidráulica do meio saturada (Ks) igual a $7.970 \mathrm{~m} \mathrm{~d}^{-1}$.

A fim de proceder ao tratamento primário, a água residuária, antes de ser aplicada nos SACs, passou por filtro orgânico constituído por coluna de bagaço de cana-de-açúcar picado, seguindo-se recomendações de Magalhães et al. (2006).

A distribuição dos tratamentos foi feita da seguinte forma: o SAC1 foi totalmente cultivado com Taboa (Typha latifolia L.); o SAC2 foi totalmente cultivado com Alternanthera (Alternanthera philoxeroides (Mart) Griseb); o SAC3 foi totalmente cultivado com Tifton 85 (Cynodon dactylon (L.) Pers.); e o SAC4,cultivado no primeiro terço com Alternanthera, no segundo terço, com taboa e no terço final, com tifton-85. 
MATOS, A. T.; FREITAS, W. S.; LO MONACO, P. A. V. Capacidade extratora de diferentes espécies vegetais cultivadas em sistemas alagados utilizados no tratamento de águas residuárias da suinocultura. Ambi-Agua, Taubaté, v. 4, n. 2, p. 31-45, 2009. (doi:10.4136/ambi-agua.84)

A taboa e a Alternanthera tiveram de ser plantadas em duas etapas. No que se refere à taboa, na primeira etapa, utilizaram-se propágulos vegetativos (rizomas) de 0,30 m de comprimento, retirando-se quase todo o sistema radicular e a parte aérea; na segunda etapa, após não ter obtido brotamento em praticamente $100 \%$ no primeiro plantio, retirou-se apenas parte do sistema radicular, sendo mantido, aproximadamente, $0,80 \mathrm{~m}$ da parte aérea. No caso da Alternanthera, na primeira etapa, foram plantados segmentos de caule com dois nós, sendo retiradas todas as folhas. Os segmentos de caule foram cobertos completamente com pequena camada de brita. Na segunda etapa, após não ter obtido brotamento em praticamente $100 \%$ no primeiro plantio, foram utilizadas de 4 a 5 nós, mantendo-se apenas metade do segmento coberto. O capim Tifton 85 foi plantado apenas uma vez, por meio de mudas com raízes densas e folhas praticamente seca.

Em cada SAC, foram aplicados $0,8 \mathrm{~m}^{3} \mathrm{~d}^{-1}$ de ARS filtrada (volume correspondente ao que é produzido por cerca de 8 a 10 animais por dia), distribuindo-se a aplicação, em igual vazão, ao longo do dia, correspondendo a um tempo de residência hidráulica aproximado de 4,8 dias.

Baseado nas análises do afluente dos filtros orgânicos, feitas ao longo do período de experimentação, nos SACs, a ARS foi aplicada numa taxa média de 154,8 $\mathrm{kg} \mathrm{ha}^{-1} \mathrm{~d}^{-1}$ de DBO e de 590,9 $\mathrm{kg} \mathrm{ha}^{-1} \mathrm{~d}^{-1}$ de DQO, estando a carga de nutrientes apresentada na Tabela 1. A taxa de aplicação utilizada neste trabalho foi um pouco superior aos $133 \mathrm{~kg} \mathrm{ha}^{-1} \mathrm{~d}^{-1}$ de DBO sugerido por Tchobanoglous e Burton (1991), entretanto foi mantida tendo em vista se tratar de aplicação em SACs, operando em condições climáticas tropicais.

Tabela 1. Cargas aplicadas, em $\mathrm{kg} \mathrm{ha}^{-1} \mathrm{~d}^{-1}$ de DBO, tomando-se as concentrações presentes na ARS afluente aos SACs, como referência.

\begin{tabular}{rcccccccccccc}
\hline \multicolumn{10}{c}{ Amostragem } & \multicolumn{1}{c}{} & média \\
\hline N-total & $\mathbf{1}^{\mathbf{a}}$ & $\mathbf{2}^{\mathbf{a}}$ & $\mathbf{3}^{\mathbf{a}}$ & $\mathbf{4}^{\mathbf{a}}$ & $\mathbf{5}^{\mathbf{a}}$ & $\mathbf{6}^{\mathbf{a}}$ & $\mathbf{7}^{\mathbf{a}}$ & $\mathbf{8}^{\mathbf{a}}$ & $\mathbf{9}^{\mathbf{a}}$ & $\mathbf{1 0}^{\mathbf{a}}$ & $\mathbf{1 1}^{\mathbf{a}}$ & \\
Amônio & 95,2 & 21,4 & 89,5 & 65,2 & 113,7 & 124,4 & 113,9 & 101,05 & 109,0 & 85,4 & 101,1 & 93,3 \\
Nitrato & 0,49 & 0,24 & 1,02 & 2,56 & 76,7 & 76,0 & 85,2 & 87,9 & 65,5 & 55,9 & 94,7 & 67,0 \\
P-total & 10,5 & 13,4 & 24,2 & 15,2 & 26,3 & 33,8 & 28,9 & 21,4 & 26,7 & 21,4 & 21,7 & 22,1 \\
K & 17,3 & 18,5 & 25,9 & 27,6 & 38,7 & 41,7 & 56,2 & 42,3 & 50,2 & 37,1 & 43,6 & 36,3 \\
Na & 5,91 & 6,12 & 7,21 & 9,33 & 13,4 & 14,4 & 15,3 & 12,5 & 14,7 & 12,1 & 13,9 & 11,3 \\
Cu & 0,04 & 0,16 & 0,28 & 0,10 & 0,16 & 0,56 & 0,22 & 0,03 & 0,35 & 0,50 & 0,32 & 0,25 \\
Zn & 0,03 & 2,22 & 3,16 & 0,02 & 2,49 & 2,61 & 2,22 & 0,63 & 2,04 & 1,01 & 0,94 & 1,58 \\
\hline
\end{tabular}

Foram feitos três cortes dos vegetais durante o período experimental, a fim de se avaliar a produtividade e os teores de nutrientes na parte aérea das plantas. O primeiro corte foi realizado no período de 5 a 12/04/05, o segundo corte no período de 24/07/05 a 4/08/05 e o terceiro corte no período de 8 a 14/11/05. Nos três SACs cultivados com apenas uma espécie de planta, amostrou-se conforme apresentado na Figura 1a e no SAC cultivado com as três espécies amostrou-se conforme apresentado na Figura 1b. Após terem sido coletadas as amostras que seriam submetidas à análise, procedeu-se o corte no restante das áreas, a fim de igualar o tamanho das plantas em toda a parcela experimental.

O material vegetal colhido foi imediatamente pesado, a fim de se determinar a produtividade de massa verde (PMV), dividindo-se a massa verde produzida pela área de coleta $(4,0 \times 1,1 \mathrm{~m})$. Após a pesagem, toda a massa verde de cada área selecionada foi imediatamente picada, sendo retiradas três amostras representativas para determinação do conteúdo de água, possibilitando cálculo do conteúdo de matéria seca e preparo para realização da análise nutricional. 
MATOS, A. T.; FREITAS, W. S.; LO MONACO, P. A. V. Capacidade extratora de diferentes espécies vegetais cultivadas em sistemas alagados utilizados no tratamento de águas residuárias da suinocultura. Ambi-Agua, Taubaté, v. 4, n. 2, p. 31-45, 2009. (doi:10.4136/ambi-agua.84)

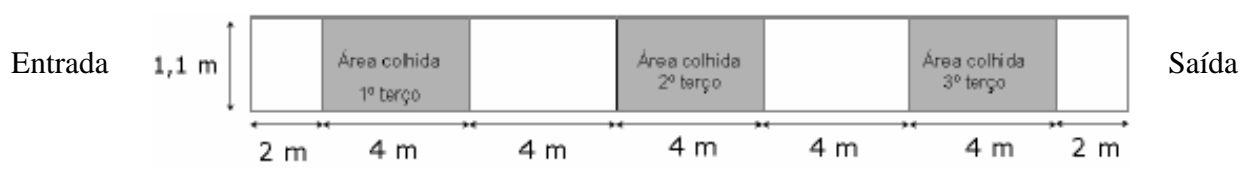

(a)

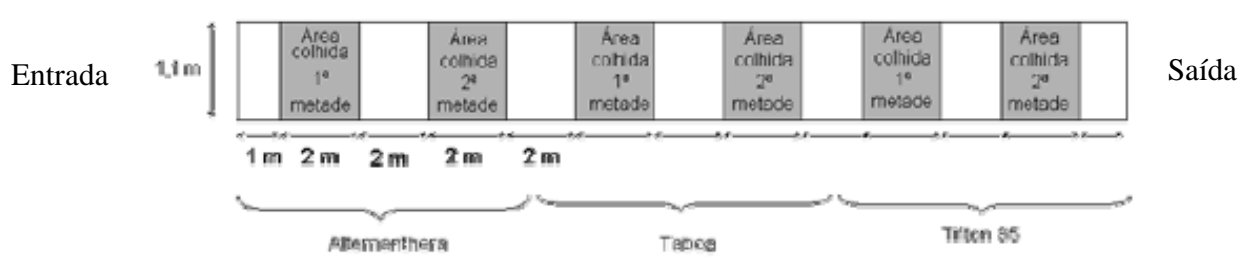

(b)

Figura 1. Croqui das áreas de colheita da massa vegetal produzida nos SAC1, SAC2 e SAC3, cultivados com apenas uma espécie de planta (a), e no SAC4, cultivado com as três espécies de planta (b).

As amostras foram colocadas em sacos de papel identificados e levadas à estufa, sob temperatura de $60^{\circ} \mathrm{C}$, com circulação de ar, até atingir massa constante (pré-secagem). Em seguida, as amostras foram trituradas em moinho tipo "Willey", com peneira de 30 "mesh" e armazenadas em sacos de papel, para posterior quantificação do conteúdo de matéria seca e realização da análise nutricional. Parte da amostra foi retirada e colocada em estufa, sob temperatura de $105^{\circ} \mathrm{C}$, até ser atingida constância na massa, retirando-se, assim, o teor de água residual e, com isso, obtendo-se a matéria seca total, em cada tratamento. A capacidade das plantas em extrair nutrientes foi obtida pelo produto da concentração do nutriente na planta e a produtividade da matéria seca.

As análises do tecido vegetal seguiram metodologia proposta por Kiehl (1985), determinando-se o nitrogênio total pela quantificação pelo processo semimicro Kjeldahl; fósforo, análise realizada por meio de digestão nítrico-perclórico da amostra e quantificada em espectrofotômetro; sódio e potássio, quantificação em fotômetro de chama, após digestão nítrico-perclórico da amostra; e cobre e zinco, pela quantificação em espectrofotômetro de absorção atômica, após digestão nítrico-perclórico da amostra.

Os dados de extração de nutrientes dos SACs 1, 2 e 3, nos três cortes efetuados, foram analisados como um fatorial 3x3x3 (3 SACs, 3 posições dentro de cada SAC e 3 repetições em cada posição), com parcelas subdivididas, distribuídas no delineamento em blocos casualizados (DBC) com 2 fatores (fator SAC e fator posições dentro de cada SAC). Quando havia efeito significativo para a interação SACxPosição no leito, comparou-se o efeito de um fator em cada nível do outro e, quando não havia efeito significativo da interação SACxPosição, os fatores eram avaliados separadamente. As médias, quando os efeitos eram significativos, foram comparadas pelo teste Tukey, a 5\% de probabilidade. Para o SAC4, foi feita uma análise descritiva dos dados da capacidade de extração, pelo fato de sua forma de amostragem se diferenciar dos demais SACs.

\section{RESULTADOS E DISCUSSÃO}

Para cálculo da quantidade de nutrientes extraídos pelas plantas foi quantificada a produtividade de matéria seca, em $\mathrm{t} \mathrm{ha}^{-1}$, das espécies vegetais cultivadas nos SACs, estando os resultados apresentados na Figura 2.

Em geral, maiores produtividades foram observadas no $3^{\circ}$ e $1^{\circ}$ cortes. Todas as plantas apresentaram bom desempenho na produtividade de matéria seca com valores médios, por 
corte efetuado, em torno de 22,2; 26,2 e 28,8 t ha ${ }^{-1}$ para os SAC1, SAC2 e SAC3, respectivamente.

Na Tabela 2 estão apresentados os valores médios da extração de nitrogênio, fósforo, potássio, sódio, cobre e zinco, com base na produtividade e na concentração presente na matéria seca da parte aérea das espécies vegetais, nos três cortes efetuados e nas três posições de coleta (primeiro, segundo e terceiro terços dos leitos) nos SAC1, SAC2 e SAC3. Os cortes de plantas efetuados no SAC4 (misto) foram feitos em duas partes de cada terço do leito, já que estes foram cultivados com plantas diferentes, estando os valores obtidos apresentados na Tabela 3. Já os percentuais de remoção de nitrogênio, fósforo, potássio, sódio, cobre e zinco pelas plantas cultivadas nos SACs utilizados no tratamento de ARS estão apresentados na Tabela 4.

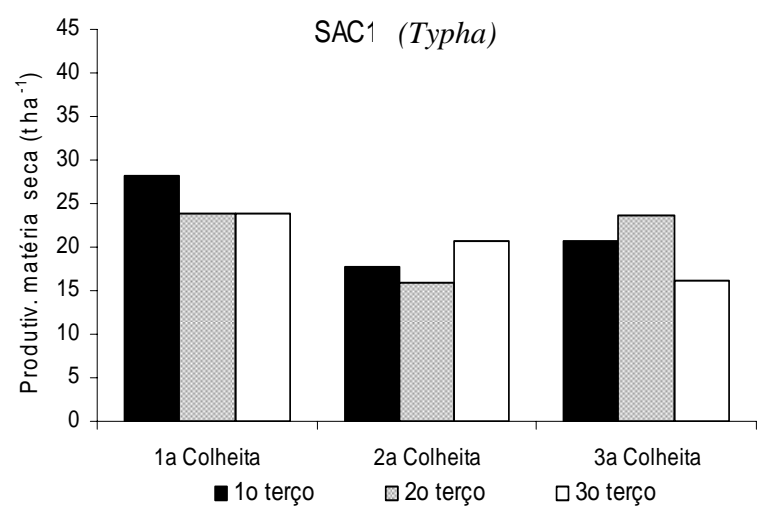

(a)

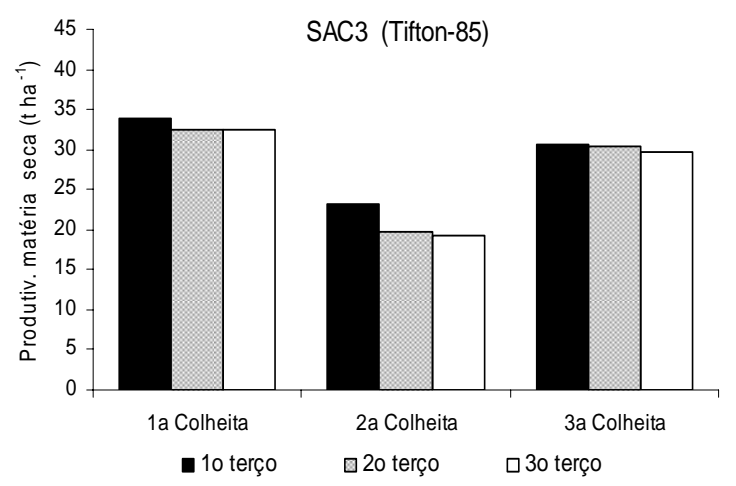

(c)

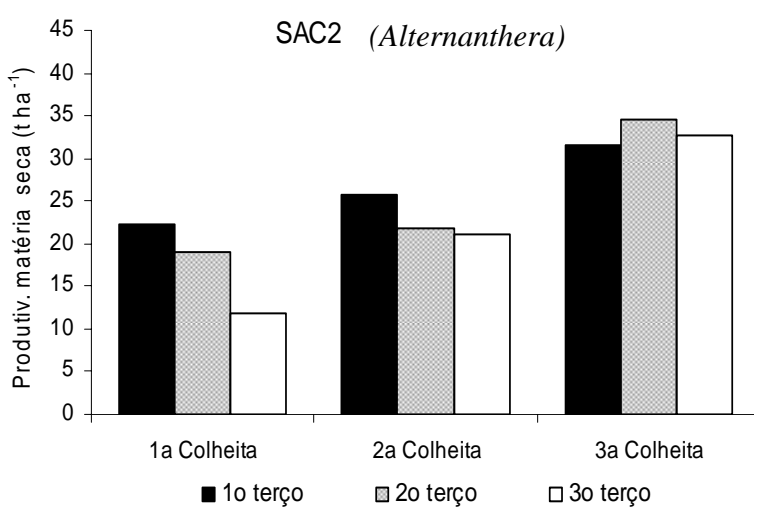

(b)

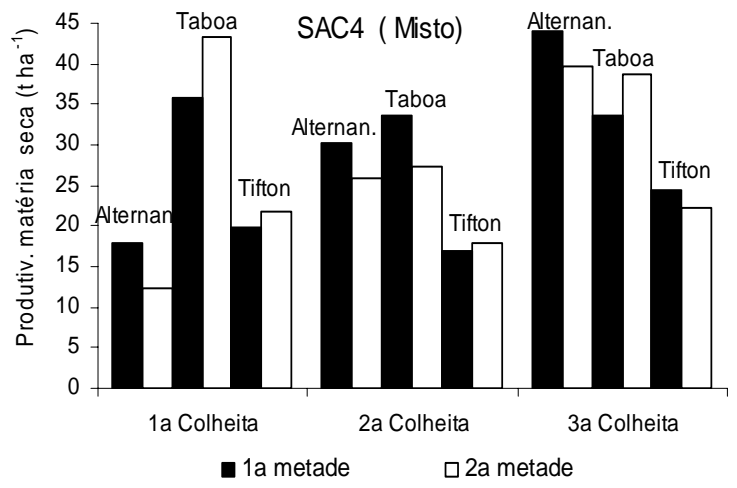

(d)

Figura 2. Valores médios da produtividade de matéria seca nos pontos de coleta ao longo do comprimento dos SACs cultivados com taboa (Typha) (a), Alternanthera (b), Tifton (c) e misto (d).

Nos $1^{\circ}$ e $3^{\circ}$ cortes, como houve efeito significativo para a interação SACxPosição no leito, comparou-se o efeito de um fator em cada nível do outro. No $2^{\circ}$ corte, como não houve efeito significativo da interação SACxPosição, os fatores foram avaliados separadamente.

Analisando-se os dados de extração de nitrogênio obtidos nos SACs (Tabela 2) verificase que, no $1^{\circ}$ corte, as plantas cultivadas nos SAC2 (Alternanthera) e SAC3 (tifton 85) apresentaram maiores extrações de $\mathrm{N}$-total apenas no $1^{\circ}$ terço dos leitos, não havendo diferenças entre os SACs no $2^{\circ}$ e $3^{\circ}$ terços dos leitos. No $2^{\circ}$ corte, as plantas do SAC2 (Alternanthera) apresentaram, em média, maior extração que as dos demais SACs, enquanto no $3^{\circ}$ corte prevaleceram maiores valores de extração de $\mathrm{N}$-total no SAC2, nos $1^{\circ}, 2^{\circ}$ e $3^{\circ}$ terços dos leitos. Analisando-se as posições de coleta de amostras de plantas no leito, 
MATOS, A. T.; FREITAS, W. S.; LO MONACO, P. A. V. Capacidade extratora de diferentes espécies vegetais cultivadas em sistemas alagados utilizados no tratamento de águas residuárias da suinocultura. Ambi-Agua, Taubaté, v. 4, n. 2, p. 31-45, 2009. (doi:10.4136/ambi-agua.84)

observa-se que, nos $1^{\circ}$ e $3^{\circ}$ cortes, em geral, maiores extrações de $\mathrm{N}$-total foram obtidas no $1^{\circ}$ terço dos leitos, apesar de não haver diferença significativa nos valores obtidos nas plantas coletadas no SAC1 e SAC3, enquanto que, no $2^{\circ}$ corte, maiores valores médios foram obtidos no $1^{\circ}$ e $3^{\circ}$ terços.

No SAC4, não foi feita análise estatística, no entanto, verifica-se que as maiores extrações foram obtidas pela Alternanthera. Além disso, houve tendência de se obter, para uma mesma planta, maiores extrações na $1^{\mathrm{a}}$ metade da área cultivada.

Os valores de extração de $\mathrm{N}$-total foram consideravelmente superiores aos encontrados por Hunt et al. (2003), nos EUA, que verificaram, em SACs de 3,6 x 33,5 m, extrações de 428 $\mathrm{kg} \mathrm{ha}^{-1} \mathrm{ano}^{-1}$ em SAC com cultivo misto de Sparganium americanum e Typha e de $338 \mathrm{~kg} \mathrm{ha}^{-1}$ ano $^{-1}$ em SAC com cultivo misto de Juncus effusus e espécies de Scipus, em tratamento de ARS, sob carga de $3 \mathrm{~kg} \mathrm{ha}^{-1} \mathrm{dia}^{-1}$ de $\mathrm{N}$-total. No entanto, as extrações obtidas pelo capim tifton 85 (SAC3), neste trabalho, foram próximas aos $552 \mathrm{~kg} \mathrm{ha}^{-1}$, obtidos por Queiroz et al. (2004), em avaliação da capacidade extratora do mesmo capim, quando cultivado sob carga de $175 \mathrm{~kg} \mathrm{ha}^{-1}$ dia $^{-1}$ de N-total, em 4 meses de aplicação contínua de ARS. Tais resultados sugerem que haja uma relação entre a carga de nitrogênio aplicada e a quantidade de nitrogênio extraído pela planta.

Os resultados apresentados nas Tabelas 2 e 3 sugerem que a Alternanthera foi, dentre as espécies avaliadas, a maior extratora de N-total e que, também, haja relação entre a carga aplicada de $\mathrm{N}$-total e a extração desse nutriente pela planta, uma vez que maiores extrações foram obtidas em posições dos leitos em que estavam presentes maiores quantidades de $\mathrm{N}$ total.

Observa-se na Tabela 4 que as plantas cultivadas no SAC2 (Alternanthera) removeram mais $\mathrm{Cu}$ da ARS, com média de 0,09\%, valores que foram superiores aos obtidos pelas plantas cultivadas nos demais SACs. O SAC4, apesar de conter um terço da área cultivado com Alternanthera, foi prejudicado pela baixa produtividade do capim tifton 85, muito inferior ao das demais espécies vegetais cultivadas nos SACs. Além disso, pode-se observar tendência de maiores remoções nas primeiras posições de amostragem, em cada SAC. Tais valores sugerem que o processo de extração de nutrientes pela Alternanthera (SAC2) e pelo sistema misto (SAC4) foi superior ao reportado por Lee et al. (2004) que, no tratamento de ARS, em Taiwan, utilizando a Eichhornia crassipes como espécie cultivada nos leitos, obtiveram extração de 2 a $4 \%$ do N-total aplicado.

Conforme pode ser observado na Tabela 2, houve, no $1^{\circ}$ corte, efeito significativo da extração de $\mathrm{P}$ pelas plantas somente entre os valores médios obtidos nas diferentes posições dos SACs e, no $3^{\circ}$ corte, somente entre os diferentes SACs. Já no $2^{\circ}$ corte, como houve efeito significativo para a interação SACxPosição, comparou-se o efeito de um fator em cada nível do outro. No $2^{\circ}$ corte, as diferenças foram significativas em todas as posições de coleta de amostras de plantas nos leitos. Maiores extrações de $\mathrm{P}$, no $2^{\circ}$ corte, na primeira posição dos SACs, foram obtidas nas plantas cultivadas no SAC2 (Alternanthera), tendo sido obtidos valores quase 2 vezes maiores que os obtidos nas plantas cultivadas no SAC1 (taboa). No $3^{\circ}$ corte, não houve diferença significativa entre a extração de $\mathrm{P}$ pelas plantas cultivadas no SAC1 (taboa) e no SAC3 (tifton 85), mas a Alternanthera apresentou capacidade extratora maior que duas vezes à obtida pela taboa. 
MATOS, A. T.; FREITAS, W. S.; LO MONACO, P. A. V. Capacidade extratora de diferentes espécies vegetais cultivadas em sistemas alagados utilizados no tratamento de águas residuárias da suinocultura. Ambi-Agua, Taubaté, v. 4, n. 2, p. 31-45, 2009. (doi:10.4136/ambi-agua.84)

Tabela 2. Valores médios da extração de nitrogênio, fósforo, potássio e sódio $\left(\mathrm{kg} \mathrm{ha}^{-1}\right)$ e de cobre e zinco (g ha $\left.{ }^{-1}\right)$, com base na análise nutricional e na produtividade de matéria seca, nos três cortes efetuados e nas três posições de coleta de amostras de plantas nos SAC1, SAC2 e SAC3.

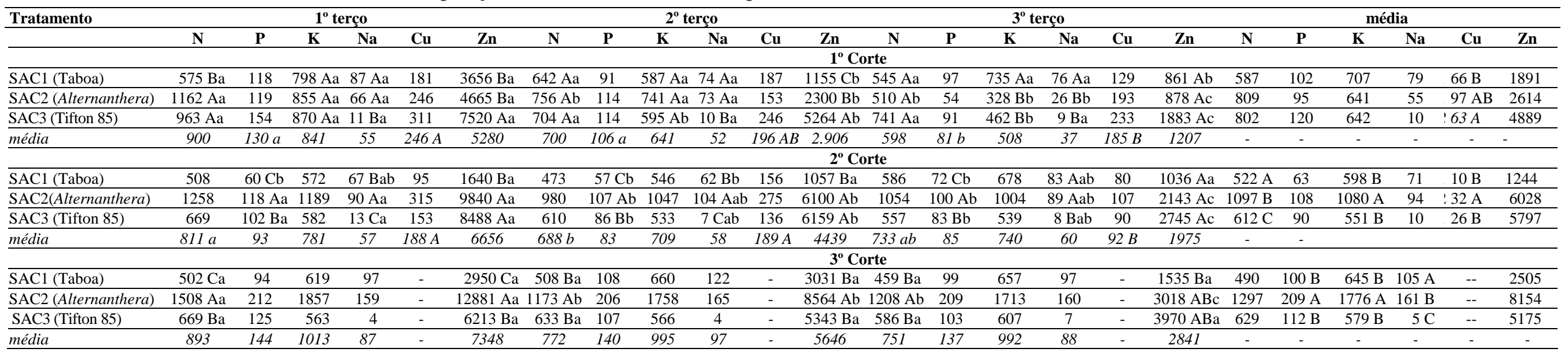

Dentro de uma mesma coluna, de um mesmo corte, médias com mesma letra maiúscula não diferem entre si, a 5\% de probabilidade, pelo teste Tukey.

Dentro de uma linha, de um mesmo corte, médias com mesma letra minúscula não diferem entre si, a 5\% de probabilidade, pelo teste Tukey.

Tabela 3. Valores médios da extração de nitrogênio, fósforo, potássio e sódio $\left(\mathrm{kg} \mathrm{ha}^{-1}\right)$ e de cobre e zinco (g ha $\left.{ }^{-1}\right)$, com base na análise nutricional e na produtividade de matéria seca, nos três cortes efetuados e nas diferentes posições de coleta das plantas no SAC4 (misto).

\begin{tabular}{|c|c|c|c|c|c|c|c|c|c|c|c|c|c|c|c|c|c|c|}
\hline \multirow[t]{3}{*}{ Tratamento } & \multicolumn{18}{|c|}{$1^{\circ}$ Corte } \\
\hline & $\mathbf{N}$ & $\mathbf{P}$ & $\mathbf{K}$ & $\mathrm{Na}$ & $\mathbf{C u}$ & $\mathbf{Z n}$ & $\mathbf{N}$ & $\mathbf{P}$ & $\mathbf{K}$ & $\mathrm{Na}$ & $\mathrm{Cu}$ & $\mathbf{Z n}$ & $\mathbf{N}$ & $\mathbf{P}$ & $\mathbf{K}$ & $\mathrm{Na}$ & $\mathbf{C u}$ & $\mathbf{Z n}$ \\
\hline & \multicolumn{6}{|c|}{$1^{a}$. Metade } & \multicolumn{6}{|c|}{$2^{\mathrm{a}}$. Metade } & \multicolumn{6}{|c|}{ média } \\
\hline SAC4 (Alternanthera) & 898 & 92 & 653 & 47,1 & 220 & 5115 & 586 & 80 & 441 & 51,6 & 215 & 5389 & 742 & 86 & 547 & 49,4 & 217,5 & 5252 \\
\hline SAC4 (Taboa) & 713 & 163 & 1065 & 139,1 & 346 & 1637 & 702 & 188 & 1190 & 150,0 & 363 & 1292 & 707 & 175,5 & 1127,5 & 144,6 & 354,5 & 1464,5 \\
\hline \multirow[t]{3}{*}{ SAC4 (Tifton 85) } & 488 & 74 & 331 & 4,7 & 180 & 768 & 509 & 80 & 405 & 6,3 & 315 & 1261 & 498 & 77 & 368 & 5,5 & 247,5 & 1014,5 \\
\hline & \multicolumn{18}{|c|}{$2^{\circ}$ Corte } \\
\hline & \multicolumn{6}{|c|}{$1^{\text {a. }}$. Metade } & \multicolumn{6}{|c|}{$2^{\mathrm{a}}$. Metade } & \multicolumn{6}{|c|}{ média } \\
\hline SAC4 (Alternanthera) & 1633 & 141 & 1473 & 102,7 & 258 & 7962 & 1262 & 129 & 1237 & 98,0 & 327 & 10827 & 1448 & 135 & 1355 & 100,4 & 292,5 & 9394,5 \\
\hline SAC4 (Taboa) & 905 & 137 & 1141 & 111,5 & 133 & 2079 & 771 & 105 & 941 & 107,6 & 98 & 931 & 838 & 121 & 1041 & 109,6 & 115,5 & 1505 \\
\hline \multirow[t]{3}{*}{ SAC4 (Tifton 85) } & 490 & 69 & 311 & 5,3 & 37 & 1038 & 597 & 78 & 309 & 6,1 & 41 & 1044 & 543 & 73,5 & 310 & 5,7 & 39 & 1041 \\
\hline & \multicolumn{18}{|c|}{$3^{\circ}$ Corte } \\
\hline & \multicolumn{6}{|c|}{$1^{\text {a }}$. Metade } & \multicolumn{6}{|c|}{$2^{\text {a }}$. Metade } & \multicolumn{6}{|c|}{ média } \\
\hline SAC4 (Alternanthera) & 2197 & 298 & 2892 & 176,9 & - & 20499 & 1866 & 246 & 2029 & 189,6 & - & 13469 & 2031 & 272 & 2460,5 & 183,3 & - & 16984 \\
\hline SAC4 (Taboa) & 748 & 164 & 866 & 129,9 & - & 1786 & 836 & 191 & 916 & 157,7 & - & 1087 & 792 & 177,5 & 891 & 143,8 & - & 1436,5 \\
\hline SAC4 (Tifton 85) & 570 & 98 & 456 & 4,3 & - & 1017 & 540 & 100 & 444 & 5,6 & - & 840 & 555 & 99 & 450 & 5,0 & - & 928,5 \\
\hline
\end{tabular}




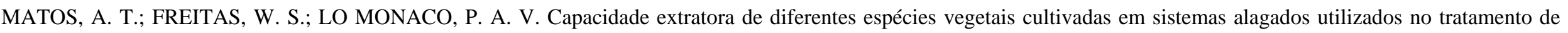
águas residuárias da suinocultura. Ambi-Agua, Taubaté, v. 4, n. 2, p. 31-45, 2009. (doi:10.4136/ambi-agua.84)

Tabela 4. Remoção de nitrogênio, fósforo, potássio, sódio, cobre e zinco pelas plantas cultivadas nos SACs utilizados no tratamento de ARS.

\begin{tabular}{|c|c|c|c|c|c|c|c|c|c|c|c|c|c|}
\hline \multirow{3}{*}{ Tratamento } & \multirow{3}{*}{ Amostragem } & \multicolumn{12}{|c|}{ Remoção (\%)* } \\
\hline & & \multicolumn{6}{|c|}{ por área amostrada } & \multicolumn{6}{|c|}{ média por SAC } \\
\hline & & $\mathbf{N}$ & $\mathbf{P}$ & $\mathbf{K}$ & $\mathrm{Na}$ & $\mathbf{C u}$ & Zn & $\mathbf{N}$ & $\mathbf{P}$ & $\mathbf{K}$ & $\mathrm{Na}$ & $\mathbf{C u}$ & $\mathbf{Z n}$ \\
\hline \multirow{3}{*}{ SAC1 (taboa) } & $1^{\circ}$ terço & 4,4 & 2,2 & 12,2 & 4,6 & 0,04 & 0,9 & \multirow{3}{*}{4,5} & \multirow{3}{*}{2,3} & \multirow{3}{*}{12,7} & \multirow{3}{*}{4,9} & \multirow{3}{*}{0,04} & \multirow{3}{*}{0,7} \\
\hline & $2^{\circ}$ terço & 4,1 & 2,1 & 11,6 & 4,2 & 0,06 & 0,6 & & & & & & \\
\hline & $3^{\circ}$ terço & 5,1 & 2,6 & 14,4 & 5,7 & 0,03 & 0,6 & & & & & & \\
\hline \multirow{3}{*}{ SAC2 (Alternanthera) } & $1^{\circ}$ terço & 10,9 & 4,2 & 25,3 & 6,2 & 0,12 & 5,4 & \multirow{3}{*}{9,5} & \multirow{3}{*}{3,9} & \multirow{3}{*}{23,0} & & \multirow{3}{*}{0,09} & \multirow{3}{*}{3,3} \\
\hline & $2^{\circ}$ terço & 8,5 & 3,8 & 22,3 & 7,1 & 0,11 & 3,3 & & & & \multirow{2}{*}{6,5} & & \\
\hline & $3^{\circ}$ terço & 9,2 & 3,6 & 21,3 & 6,1 & 0,04 & 1,2 & & & & & & \\
\hline \multirow{3}{*}{ SAC3 (tifton 85) } & $1^{\circ}$ terço & 5,8 & 3,7 & 12,4 & 0,9 & 0,06 & 4,6 & \multirow{3}{*}{5,3} & \multirow{3}{*}{3,2} & \multirow{3}{*}{11,7} & \multirow{3}{*}{0,7} & \multirow{3}{*}{0,05} & \multirow{3}{*}{3,2} \\
\hline & $2^{\circ}$ terço & 5,3 & 3,1 & 11,3 & 0,5 & 0,05 & 3,4 & & & & & & \\
\hline & $3^{\circ}$ terço & 4,8 & 3,0 & 11,5 & 0,6 & 0,03 & 1,5 & & & & & & \\
\hline \multirow{2}{*}{ SAC4 (Alternanthera) } & $1^{\mathrm{a}}$ metade & 14,2 & 5,0 & 31,3 & 7,0 & 0,10 & 4,3 & \multirow{6}{*}{8,2} & \multirow{6}{*}{3,9} & \multirow{6}{*}{19,2} & \multirow{6}{*}{4,9} & \multirow{6}{*}{0,06} & \multirow{6}{*}{2,2} \\
\hline & $2^{\mathrm{a}}$ metade & 11,0 & 4,6 & 26,3 & 6,7 & 0,13 & 5,9 & & & & & & \\
\hline SAC4 (taboa) & $1^{\mathrm{a}}$ metade & 7,9 & 4,9 & 24,3 & 7,6 & 0,05 & 1,1 & & & & & & \\
\hline SAC4 (taDoa) & $2^{\mathrm{a}}$ metade & 6,7 & 3,7 & 20,0 & 7,4 & 0,04 & 0,5 & & & & & & \\
\hline SAC4 (tifton 85) & $1^{\mathrm{a}}$ metade & 4,3 & 2,5 & 6,6 & 0,4 & 0,01 & 0,6 & & & & & & \\
\hline SAC4 (titton 85) & $2^{\mathrm{a}}$ metade & 5,2 & 2,8 & 6,6 & 0,4 & 0,02 & 0,6 & & & & & & \\
\hline
\end{tabular}

* Baseada nas cargas de $11.507 \mathrm{~kg} \mathrm{ha}^{-1}$ de N-total, $2.792 \mathrm{~kg} \mathrm{ha}^{-1}$ de P-total, $4.705 \mathrm{~kg} \mathrm{ha}^{-1}$ de K, $1.459 \mathrm{~kg} \mathrm{ha}^{-1} \mathrm{de} \mathrm{Na}_{26} \mathrm{~kg}^{-1} \mathrm{de}^{-1} \mathrm{Cu}$ e $183 \mathrm{~kg}^{-1} \mathrm{de}_{\mathrm{Zn}}$ aplicado entre o $1^{\circ}$ e o $2^{\circ}$ cortes (período de 110 dias de operação do sistema) 
MATOS, A. T.; FREITAS, W. S.; LO MONACO, P. A. V. Capacidade extratora de diferentes espécies vegetais cultivadas em sistemas alagados utilizados no tratamento de águas residuárias da suinocultura. Ambi-Agua, Taubaté, v. 4, n. 2, p. 31-45, 2009. (doi:10.4136/ambi-agua.84)

Analisando-se o efeito da posição de coleta das amostras de plantas da Alternathera e do tifton 85 , no $2^{\circ}$ corte, verificou-se que a maior extração de $\mathrm{P}$ ocorreu no $1^{\mathrm{o}}$ terço dos SACs. Por ser $\mathrm{P}$ um elemento químico fortemente associado à matéria orgânica, a grande retenção de material sólido no terço inicial dos SACs possibilitou maior disponibilização desse nutriente para as plantas. No SAC cultivado com a taboa (SAC1), a extração ficou igualmente distribuída ao longo do leito. No $3^{\circ}$ corte, não foi encontrado efeito da posição das plantas na extração de P.

Os dados de extração de $\mathrm{P}$ nas plantas do SAC4 não foram submetidos à análise estatística, no entanto, observou-se tendência das maiores extrações serem obtidas pela taboa no $1^{\circ}$ corte e pela Alternanthera no $2^{\circ}$ e $3^{\circ}$ cortes. Nesse SAC, não houve tendência de se obter maiores extrações de $\mathrm{P}$ na $1^{\mathrm{a}}$ metade em relação à $2^{\mathrm{a}}$ metade das zonas cultivadas por cada planta.

As extrações de P obtidas pelo capim tifton 85 (SAC3) foram superiores aos $61 \mathrm{~kg} \mathrm{ha}^{-1}$ obtidos por Queiroz et al. (2004), quando aplicaram, continuamente, durante 4 meses, no mesmo capim, ARS numa carga de $91 \mathrm{~kg} \mathrm{ha}^{-1} \mathrm{dia}^{-1}$ de P.

Com base nos dados apresentados nas Tabelas 2 e 3, a Alternanthera destacou-se com a maior extratora de P da ARS, não tendo havido grandes diferenças entre o que foi extraído pela taboa e pelo tifton 85. A extração média de $107 \mathrm{~kg} \mathrm{ha}^{-1}$ de $\mathrm{P}$ pelo capim tifton 85 , valor inferior ao obtido pela Alternanthera, que foi de $134 \mathrm{~kg} \mathrm{ha}^{-1}$, não deixa de ser negativamente surpreendente, já que esse capim é considerado grande extrator desse nutriente (Queiroz et al., 2004). Acredita-se, com base nesses resultados, que a Alternanthera tenha se adaptado melhor ao meio de seu cultivo. Os resultados obtidos indicaram, também, que houve estreita relação entre a quantidade presente de $\mathrm{P}$ e sua extração pelas plantas, uma vez que maiores extrações foram obtidas em locais onde este estava mais concentrado (principalmente no início do SAC2 e SAC3).

Observa-se na Tabela 4 que as plantas cultivadas no SAC2 e SAC4 apresentaram remoções de P-total superiores às obtidas pelas plantas cultivadas nos demais SACs, com médias de 3,9\%. Sendo o P um elemento de difícil remoção em sistemas convencionais de tratamento de águas residuárias, tal valor pode ser considerado expressivo. As extrações de nutrientes pelas plantas foram muito superiores às obtidas por Lee et al. (2004), no tratamento de ARS, em Taiwan, utilizando aguapé (Eichhornia crassipes), que foram de apenas 0,1 e $1,2 \%$.

Não existe muita informação sobre o comportamento de metais alcalinos em SACs utilizados no tratamento de águas residuárias, uma vez que esse elemento químico não está, normalmente, associado à qualidade do efluente de sistema de tratamento. Todavia, o potássio e o sódio estão incluídos entre os nutrientes absorvidos pelos vegetais e podem causar problemas quando presentes em altas concentrações no solo (Matos e Sediyama, 1995), prejudicando um possível aproveitamento agrícola do efluente dos SACs. Por essa razão, suas concentrações devem ser, necessariamente, mensuradas.

No $1^{\circ}$ corte, como houve efeito significativo, em termos de extração de potássio pelas plantas, para a interação SACxPosição, comparou-se o efeito de um fator em cada nível do outro. Nos $2^{\circ}$ e $3^{\circ}$ cortes, houve efeito significativo somente entre os SACs.

No $1^{\circ}$ corte, foi encontrada diferença significativa entre a extração de K pelas plantas cultivadas nos SACs somente no $3^{\circ}$ terço de cada SAC, com maior valor de extração obtido pela taboa (SAC1), com uma remoção de $735 \mathrm{~kg} \mathrm{ha}^{-1}$, não havendo diferença significativa entre a extração de nutrientes proporcionadas pelas plantas cultivadas nas demais posições de amostragem. Maiores extrações de K pela Alternanthera (SAC2) foram obtidas no $2^{\circ}$ e $3^{\circ}$ cortes, ocasião em que foram obtidos valores médios cerca de 2 vezes maiores que os obtidos nos demais SACs. 
MATOS, A. T.; FREITAS, W. S.; LO MONACO, P. A. V. Capacidade extratora de diferentes espécies vegetais cultivadas em sistemas alagados utilizados no tratamento de águas residuárias da suinocultura. Ambi-Agua, Taubaté, v. 4, n. 2, p. 31-45, 2009. (doi:10.4136/ambi-agua.84)

Tomando-se como referência a posição de coleta de amostras de plantas nos SACs, no $1^{\circ}$ corte, verifica-se que maiores extrações de K ocorreram no $1^{\circ}$ terço pelo capim tifton 85 , no $1^{\circ}$ e $2^{\circ}$ terços pela Alternanthera, e de forma igualmente distribuída nos três terços, pela taboa. Acredita-se que a maior permeabilidade do meio no SAC, proporcionado pelo desenvolvimento radicular da taboa, possa ter favorecido o deslocamento do potássio no leito.

Os resultados obtidos no SAC4 não foram submetidos à análise estatística, no entanto, pode-se observar que maiores extrações de $\mathrm{K}$ foram obtidas pela taboa, no $1^{\circ}$ corte, e pela Alternanthera, no $2^{\circ}$ e $3^{\circ}$ cortes. Não houve tendência em se obter maiores extrações na $1^{\mathrm{a}}$ metade da zona de cultivo em relação à $2^{\mathrm{a}}$ metade, provavelmente devido à alta solubilidade e mobilidade desse cátion no meio poroso.

As extrações de K obtidas pelo capim tifton 85 cultivados no SAC3 foram superiores aos $591 \mathrm{~kg} \mathrm{ha}^{-1}$ obtidos, pelo mesmo capim, em experimento conduzido por Queiroz et al. (2004), no qual se aplicou no solo, continuamente, durante 4 meses, ARS numa carga de $91 \mathrm{~kg} \mathrm{ha}^{-1}$ dia $^{-1}$ de K. Com base nos dados apresentados nas Tabelas 2 e 3, pode-se verificar que a Alternanthera apresentou as maiores extrações de $\mathrm{K}$, não havendo, no entanto, grandes diferenças em relação ao que foi obtido pela taboa e pelo tifton 85 .

Observa-se na Tabela 4 que as plantas cultivadas no SAC2 e SAC4 apresentaram remoções de $\mathrm{K}$ superiores às obtidos pelas plantas cultivadas nos demais SACs, com médias de 23 e 19,2\%, respectivamente. Pode-se observar que a tendência em se obter maiores remoções nas primeiras posições de amostragem de plantas é muito menor que as verificadas em relação aos nutrientes $\mathrm{N}$ e $\mathrm{P}$, debitando-se à maior mobilidade desse elemento químico os resultados obtidos. O processo de extração de nutrientes pela Alternanthera foi responsável por uma retirada de $23 \%$ de todo o $\mathrm{K}$ aplicado via ARS. Considerando-se que o K é um elemento químico de difícil remoção em sistemas convencionais de tratamento, os resultados obtidos podem ser considerados muito expressivos e de grande valor para o tratamento de águas residuárias.

Nos $1^{\circ}$ e $2^{\circ}$ cortes, como houve efeito significativo, no que se refere à extração de sódio pelas plantas, para a interação SACxPosição, comparou-se o efeito de um fator em cada nível do outro. No $3^{\circ}$ corte, houve efeito significativo somente entre os SACs.

No $1^{\circ}$ corte, prevaleceram maiores extrações de Na pelas plantas cultivadas nos SAC1 e SAC2, não havendo diferenças significativas entre as extrações obtidas no $1^{\circ}$ e $2^{\circ}$ terço dos leitos. No $2^{\circ}$ corte, maiores extrações foram obtidas pelas plantas cultivadas no SAC2, seguidas pelas cultivadas nos SAC1 e SAC3.

Analisando-se as posições de coleta de amostras de plantas, observa-se que, em média, as extrações de $\mathrm{Na}$ pelas plantas foram relativamente bem distribuídas ao longo de todo o comprimento do leito, de forma semelhante ao que foi obtido em relação ao K.

Os resultados de extração de Na pelas plantas, obtidos no SAC4, não foram submetidos à análise estatística, no entanto, pode-se observar tendência de maiores extrações realizadas pela taboa, no $1^{\circ}$ e $2^{\circ}$ cortes, e pela Alternanthera, no $3^{\circ}$ corte. Diferentemente do que ocorreu em relação aos outros nutrientes avaliados, houve tendência de se obter maiores extrações na $2^{a}$ metade, quando comparado ao que foi obtido na $1^{\mathrm{a}}$ metade da zona de cultivo de cada planta. Nesse caso, a grande solubilidade e mobilidade do cátion, associada, possivelmente, a condições químicas e físicas mais adequadas no meio poroso, podem ser explicações para o ocorrido.

As extrações de Na obtidas pelo capim tifton 85 ( SAC3), apresentadas na Tabela 4, foram muito superiores aos 6,6 $\mathrm{kg} \mathrm{ha}^{-1}$ obtidos por Queiroz et al. (2004), quando aplicaram, continuamente, durante 4 meses, no mesmo capim, ARS numa carga de $15 \mathrm{~kg} \mathrm{ha}^{-1} \mathrm{dia}^{-1} \mathrm{de}$ Na.

Com base nos dados apresentados nas Tabelas 2 e 3, verifica-se que a Alternanthera e a taboa foram as maiores extratoras de $\mathrm{Na}$, enquanto o capim tifton 85 apresentou extrações 
MATOS, A. T.; FREITAS, W. S.; LO MONACO, P. A. V. Capacidade extratora de diferentes espécies vegetais cultivadas em sistemas alagados utilizados no tratamento de águas residuárias da suinocultura. Ambi-Agua, Taubaté, v. 4, n. 2, p. 31-45, 2009. (doi:10.4136/ambi-agua.84)

muitos abaixo das obtidas por essas plantas. Observa-se, na Tabela 4, que a Alternanthera (SAC2) apresentou remoções superiores às obtidas pelas demais plantas, com valor médio de 6,5\%. O SAC4, como foi constituído por três espécies diferentes de plantas, foi prejudicado pelo baixo desempenho do capim tifton 85 na remoção de Na.

Não houve efeito significativo, no que se refere à extração de cobre pelas plantas, da interação SACxPosição, entretanto, como houve significância de cada fator, os níveis destes foram discutidos separadamente. Maiores extrações de $\mathrm{Cu}$, no $1^{\circ}$ corte, foram obtidas nas plantas cultivadas no SAC3, SAC2 e SAC1, com médias de 263, 197 e $166 \mathrm{~g} \mathrm{ha}^{-1}$, respectivamente, enquanto que, no $2^{\circ}$ corte, maiores extrações foram obtidas pelas plantas cultivadas no SAC2, não havendo diferença significativa entre o que foi extraído nos SAC1 e SAC3.

Analisando-se a posição de coleta de amostras de plantas nos leitos, observa-se que, em média, maiores extrações de $\mathrm{Cu}$, no $1^{\circ}$ corte das plantas, foram obtidas pela Alternanthera e, no $2^{\circ}$ corte, pela Alternanthera e pelo tifton 85 .

Os resultados obtidos no SAC4 não foram submetidos à análise estatística, no entanto, pode-se observar tendências de maiores extrações serem obtidas pela taboa, no $1^{\circ}$ corte, e pela Alternanthera, no $2^{\circ}$ corte. Não foi observada tendência de influência da posição de coleta de amostras de plantas na extração de $\mathrm{Cu}$, o que evidenciou mais homogênea distribuição da extração pelas plantas ao longo do leito dos SACs.

As extrações de $\mathrm{Cu}$ obtidas pelas plantas cultivadas no SAC3 (tifton 85) foram, em média, próximas aos $180 \mathrm{~g} \mathrm{ha}^{-1}$ obtidas pelo mesmo capim, em experimento conduzido por Queiroz et al.(2004), quando aplicaram, continuamente, durante 4 meses, ARS numa carga de $1,2 \mathrm{~kg} \mathrm{ha}^{-1} \mathrm{dia}^{-1}$ de Cu.

Observa-se que as três espécies de plantas apresentaram valores próximos de extração de $\mathrm{Cu}$, sendo que o tifton 85 apresentou, no SAC4, desempenho muito inferior ao obtido pelas outras plantas e inclusive por ele mesmo, no SAC3, devido à baixa produtividade de matéria seca que apresentou no SAC de cultivo misto.

Na Tabela 4, está apresentada uma estimativa da contribuição das plantas na remoção de $\mathrm{Cu}$, nos 4 SACs. Observa-se, nessa Tabela, que as plantas cultivadas no SAC2 (Alternanthera) removeram mais $\mathrm{Cu}$ da $\mathrm{ARS}$, com média de 0,09\%, valores que foram superiores aos obtidos pelas plantas cultivadas nos demais SACs. O SAC4, apesar de conter um terço da área cultivado com Alternanthera, foi prejudicado pela baixa produtividade do capim tifton 85, muito inferior ao das demais espécies vegetais cultivadas nos SACs.

A remoção de $\mathrm{Cu}$ pelas plantas cultivadas nos SACs deve ser considerada muito baixa, quando comparada às obtidas na remoção de outros nutrientes, mas está próxima dos valores obtidos por Lim et al. (2001), em experimentos com SACs cultivados (taboa) e não cultivados, que verificaram que menos de $1 \%$ do cobre introduzido nos SACs foram extraídos pela taboa. A forte complexação/quelação do $\mathrm{Cu}$ no material orgânico (Matos e Sediyama, 1995; Lo Monaco et al., 2002) proporcionou menor disponibilidade desse micronutriente para ser absorvido pelas plantas, razão pela qual sua extração é baixa quando comparada à de outros nutrientes aportados ao sistema.

Como houve efeito significativo, no que se refere à extração de Zn pelas plantas, para a interação SACxPosição, nos três cortes das plantas, comparou-se o efeito de um fator em cada nível, em cada corte.

Comparando-se os resultados de extração de Zn entres as plantas cultivadas nos SACs, apresentados na Tabela 2, verifica-se que, no $1^{\circ}$ corte, os maiores valores foram obtidos pelas cultivadas no SAC3 (tifton 85), enquanto que, nos $2^{\circ}$ e $3^{\circ}$ cortes, maiores extrações, em todos as posições de coleta, foram obtidas pelas plantas cultivadas nos SAC2 (Alternathera) e SAC3 (tifton 85). 
Comparando-se os resultados de extração de Zn obtidos nas diferentes posições de coletas das plantas, verifica-se que, no $1^{\circ}$ e $2^{\circ}$ cortes, as maiores extrações ocorreram, à exceção da obtida no SAC1, no $2^{\circ}$ corte, no $1^{\circ}$ terço do leito. No $3^{\circ}$ corte, essa superioridade do $1^{\circ}$ terço na extração do metal só prevaleceu no SAC2. A maior presença de Zn no início dos SACs, em decorrência de uma maior retenção de material orgânico, pode explicar, ao menos parcialmente, os resultados obtidos.

Os resultados obtidos no SAC4 não foram submetidos à análise estatística, no entanto, observa-se que Alternanthera apresentou extrações consideravelmente superiores às obtidas pelas demais espécies vegetais. A não ser por ocasião do $3^{\circ}$ corte, não foi verificada maior extração de Zn nas plantas posicionadas na primeira metade da sua zona de cultivo.

As extrações de Zn obtidas pelo capim tifton 85 (SAC3) foram muito superiores aos $1.490 \mathrm{~kg} \mathrm{ha}^{-1}$ obtidas pelo mesmo capim, em experimento conduzido por Queiroz et al.(2004), quando aplicaram, continuamente, durante 4 meses, ARS numa carga de $14,5 \mathrm{~kg} \mathrm{ha}^{-1} \mathrm{dia}^{-1} \mathrm{de}$ $\mathrm{Zn}$, tanto pela maior produtividade quanto pelo maior conteúdo de Zn na matéria seca.

Com base nos dados apresentados nas Tabelas 2 e 3, pode-se afirmar que a Alternanthera foi grande extratora de Zn e que há uma relação entre a quantidade presente e a extração pelas plantas.

Observa-se, com base nos dados apresentados na Tabela 4, que as plantas cultivadas no SAC2 e SAC3 removeram mais Zn que aquelas cultivadas no SAC1. Os menores valores de remoção obtidos nas plantas cultivadas no SAC1 estão associados aos baixos valores na concentração de Zn encontradas na matéria seca da taboa, quando comparados aos obtidos na Alternanthera e no tifton 85. Menores valores observados no tifton 85, no SAC4, estão associados à sua menor produtividade e à menor concentração de Zn na matéria seca, quando comparado aos obtidos pelo capim tifton 85 , cultivado no SAC3.

\section{CONCLUSÕES}

Com base nos resultados obtidos com a aplicação de água residuária da suinocultura em sistema alagado construído (SAC), pode-se concluir que:

- a Alternanthera foi a espécie que apresentou maior capacidade extratora de nutrientes, chegando a extrair aproximadamente 9,5 e 23\% de todo o N-total e K aplicados via ARS;

- no geral, verificou-se tendência de maiores remoções pelas plantas posicionadas no início dos SACs;

- houve baixa remoção de cobre em todos os SACs cultivados;

- com relação ao tipo de planta a ser utilizada, recomenda-se a utilização da Alternanthera, por ter apresentado maior concentração de nutrientes na matéria seca, ou o Tifton 85, caso o produtor deseje aproveitá-lo na alimentação animal.

\section{AGRADECIMENTOS}

Ao CNPq-CT-Hidro, Conselho Nacional de Desenvolvimento Científico e Tecnológico Fundo Setorial de Recursos Hídricos, pelo financiamento do projeto.

\section{REFERÊNCIAS}

BRASIL, M. S.; MATOS, A. T.; SILVA, C. M.; CECON, P. R.; SOARES, A. A. Modeling of pollution removal in constructed wetlands with horizontal subsurface flow. Agricultural Engineering Research, v. 13, n. 2, p. 48-56, 2007.

BRIX, H. Do macrophytes play a role in constructed treatment wetlands? Water Science Technology, v. 35, n. 5, p.11-17, 1997. 
CAMPOS, J. R. Tratamento de esgotos sanitários por processo anaeróbio e disposição controlada no solo. In: CAMPOS, JOSÉ ROBERTO (Coord.). Rio de Janeiro: ABES. 1999. 464p. Projeto PROSAB.

DIESEL, R.; MIRANDA, C. R.; PERDOMO, C. C. Coletânea de tecnologias sobre dejetos suínos. Boletim Informativo BIPERS, Concórdia, v. 10, n. 14, p. 31, 2002.

FIA, R.; MATOS, A. T.; FERREIRA, P. A.; TEODORO, P. E. P.; SCHUERY, F. C.; LUIZ, F. A. R. Desempenho agronômico da thypha sp. e alternanthera philoxeroides mart utilizadas no tratamento de águas residuárias da lavagem e descascamento/despolpa dos frutos do cafeeiro em sistema alagado construído. Revista Engenharia na Agricultura, v. 16, n. 04, p.436-448, 2008.

HUNT, P., G.; MATHENY, T. A.; SZOGI, A., A. Denitrification in Constructed Wetlands Used for Treatment of Swine Wastewater. J. Environ. Qual., v. 32, p. 727-735, 2003.

KIEHL, E. L. Fertilizantes orgânicos. Piracicaba: Agronômica Ceres, 1985. 492 p.

KONZEN, E. A. Aproveitamento de dejetos líquidos de suínos para fertirrigação e fertilização em grandes culturas. Sete Lagoas: Embrapa - CNPMS, 2003. 11p. (Circular técnica, 32).

LANGERGRABER, G. The role plant uptake on the removal of organic matter and nutrients in subsuface flow constructed wetlands: a simulation study. In: INTERNATIONAL CONFERENCE ON WASTE STABILIZATION PONDS, 6. AND INTERNATIONAL CONFERENCE ON WETLAND SYSTEMS FOR WATER POLLUTION CONTROL, 9., Avignon, 2004. Proceedings... Avignon: IWA/Astee, 1 CD-ROM.

LAUTENSCHLAGER, S. R. Modelagem do desempenho de Wetlands construídas. 2001. 90f. Dissertação (Mestrado em Engenharia Hidráulica) - Escola Politécnica, Universidade de São Paulo, São Paulo, 2001.

LEE, C. Y.; LEE, C. C.; LEE, F. Y.; TSENG, S. K.; LIAO, C. J. Performance of subsurface flow constructed wetland taking pretreated swine effluent under heavy loads. Bioresource Technology, n. 92, p.173-179, 2004.

LIM, P. E.; WONG, T. F.; LIM, D. V. Oxygen demand, nitrogen and copper removal by freewater-surface and subsurface-flow constructed wetlands under tropical conditions. Environment International, v. 26, n. 5-6, p. 425-431, 2001.

Lo MONACO, P. A.; MATOS, A. T.; MARTINEZ, M. A.; JORDÃO, C. P. Eficiência de materiais orgânicos filtrantes no tratamento de águas residuárias da lavagem e despolpa dos frutos do cafeeiro. Revista Engenharia na Agricultura, v. 10, n. 1-4, p. 40-47, 2002.

MAGAlHÃES, M. A.; MATOS, A. T.; DENICULI, W.; TINOCO, I. F. F. Operação de filtros orgânicos utilizados no tratamento de águas residuárias de suinocultura. Revista Brasileira de Engenharia Agrícola e Ambiental, Campina Grande, v. 10, n. 2, p. $472-$ 478, 2006.

MANDER, U.; LÕHMUS, K.; KUUSEMETS, V.; TEITER, S.; NURK; K.; Dynamics of nitrogen and phosphorus budgets in a horizontal subsurface flow constructed wetland. In: INTERNATIONAL CONFERENCE ON WASTE STABILIZATION PONDS, 6. AND INTERNATIONAL CONFERENCE ON WETLAND SYSTEMS FOR WATER POLLUTION CONTROL, 9., Avignon, 2004. Proceedings... Avignon: IWA/Astee, 2004. 1 CD-ROM. 
MARQUES, D. M. Terras Úmidas Construídas de Fluxo Subsuperficial. In: CAMPOS, R. (Coord.). Tratamento de esgotos sanitários por processo anaeróbio e disposição controlada no solo. Projeto PROSAB. Rio de Janeiro: ABES, 1999. p. 409-435.

MATOS, A. T.; Lo MONACO, P. A. Tratamento e aproveitamento agrícola de resíduos sólidos e líquidos da lavagem e despolpa de frutos do cafeeiro. Viçosa: UFV, 2003. 68p.

MATOS, A. T.; SEDIYAMA, M. A. N. Riscos potenciais ao ambiente pela aplicação de dejetos líquidos de suínos ou compostos orgânicos no solo. In: SEMINÁRIO MINEIRO SOBRE MANEJO E UTILIZAÇÃO DE DEJETOS DE SUÍNOS, 1., 1995, Ponte Nova. Anais... Ponte Nova: EPAMIG/EMATER/UFV/ASSUVAP, 1995. p.45-54.

MATOS, A. T.; ABRAHÃO, S. S.; PEREIRA, O. G. Desempenho agronômico de capim tifton 85 (cynodon spp) cultivado em sistemas alagados construídos utilizados no tratamento de água residuária de laticínios. Revista Ambi-Água, Taubaté, v. 3, n. 1, p. 43-53, 2008.

QUEIROZ, F. M.; MATOS, A. T.; PEREIRA, O. G.; OLIVEIRA, R. A.; LEMOS, A. L. Características químicas do solo e absorção de nutrientes por gramíneas em rampas de tratamento de águas residuárias da suinocultura. Revista Engenharia na Agricultura, v. 12, n. 2, p. 77-90, 2004.

REEDY, K. R.; DeBUSK, W. F. Nutrient removal potential of selected aquatic macrophytes. J. Environmental Quality, v. 19, p. 261, 1985.

TCHOBANOGLOUS, G.; BURTON, L. Wastewater engineering, treatment, disposal, and reuse. 3. ed. New York: McGraw-Hill, 1991.

UNITED STATES ENVIRONMENTAL PROTECTION AGENCY. Design manual on constructed wetlands and aquatic plant systems for municipal wastwater treatment, Cincinnati: EPA/625/1-88/022, CERI, 1988.

VYMAZAL, J. Removal of phosphorus via harvesting of emergent vegetation in constructed wetlands for wastewater treatment. In: INTERNATIONAL CONFERENCE ON WASTE STABILIZATION PONDS, 6. AND INTERNATIONAL CONFERENCE ON WETLAND SYSTEMS FOR WATER POLLUTION CONTROL, 9., Avignon, 2004. Proceedings... Avignon: IWA/Astee, 2004. 1 CD-ROM.

WETLAND INTERNATIONAL. The use of constructed wetlands for wastewater treatment. Malaysia Office, 2003. Disponível em: <http://www.wetlands.org/pubs\&/ConstructedWetlands.htm> Acesso em: 27 agosto 2003.

YE, Z. H.; WHITING, S.; LIN, N., Z., Q.; LYTLE, C., M.; QIAN, J., H.; TERRY, N. Removal and Distribution of Iron, Manganese, Cobalt, and Nickel within a Pennsylvania Constructed Wetland Treating Coal Combustion By-Product Leachate, Journal of Environmental Quality, v. 30, p. 1464-1473, 2001. 